\title{
(6)
}

Verónica Samper*

\section{INDIA Y SU FUTURO}

India, la mayor democracia del mundo, está determinada por múltiples condicionantes políticos, económicos, regionales y sociales que marcan su presente y futuro. Si bien la comparativa con China es inevitable, India no será la próxima China. India necesita ser entendida en sus propios términos; el país sigue su propio ritmo. Los retos que le depara el futuro son, cuando menos, desafiantes, empezando por minimizar en todo lo posible los efectos devastadores de la pandemia COVID-19 en el país, para luego hacer frente a cuestiones más estructurales. En el otro lado de la balanza, India dispone de abundantes recursos y nuevas oportunidades.

Palabras clave: India, población, servicios, federalismo, diáspora, cambio climático, infraestructuras, inversión, cohesión.

Clasificación JEL: D24, D33, D72, E66, F14, J11, J62.

\section{The Modi Mantra ${ }^{1}$}

El concepto de «mantra» es de origen sánscrito, cuya traducción literal es «instrumento mental». Los mantras se recitan para instar a la divinidad; tienen, por tanto, una connotación religiosa o más bien espiritual, por lo que todo hindú sigue el dictado de sus mantras en la vida, como sigue las enseñanzas de su gurú?

Modi, un hindú militante, ha adoptado varios mantras desde que comenzó su andadura política hacia el Gobierno de India. Tal vez el más destacado sea sabka sath, sabka vikas, sabka

\footnotetext{
* Técnico Comercial y Economista del Estado. Versión de septiembre de 2020.

DOI: https:/doi.org/10.32796/bice.2020.3128.7096

1 El título está tomado de un artículo del medio India Today, agosto de 2020, recogido en la bibliografía.

2 Es sorprendente como los gurús determinan las decisiones importantes en la vida de los indios tanto en lo profesional como en lo personal en el plano político, de los negocios, las bodas, etc.; todo es consultado.
}

vishwas, mantra que hace un llamamiento a la unión de los 1.300 millones de indios: «Apoyo a todos, desarrollo para todos, confianza para todos». Este mantra vendría acompañado del siguiente Atmanirbhar Bharat, o una India autosuficiente y resistente e integrada en la economía global.

Modi se ha convertido en mucho más que un líder político para una amplia mayoría del país. Es el gurú, el visionario que presenta un proyecto ambicioso ante los indios, destacando su antiguo pasado glorioso, con un trasfondo religioso (hinduista), una política exterior dura (China y Pakistán), una apuesta por la liberalización económica y la privatización ${ }^{3}$, la atracción de inversión extranjera (su gran programa Make in India y su obsesión por la posición $\triangleright$

3 No hay más que leer el último Economic Survey 2019-2020, del Ministerio de Finanzas, con múltiples referencias «a la mano invisible de Adam Smith" y a la no intervención. 
del país en el ranking Ease of Doing Business). Todo ello no exento de una escalada proteccionista frente al exterior, como ponen de manifiesto el aumento en los aranceles, la exigencia creciente de contenido local en las licitaciones públicas, así como el programa Self-Reliant India presentado en la era de la COVID-19 y que no es más que una deriva de carácter cada vez más nacionalista y cerrada del programa nacional Make in India.

Todo lo anterior conjugado con medidas reformistas como la desmonetización de 2016, la entrada en vigor del GST (Good \& Services Tax, un IVA único para todos los territorios y estados, que ha acabado con la miscelánea de diferentes regímenes fiscales y arancelarios entre estados), un nuevo Código de Insolvencia y Bancarrota, el Programa de Inclusión Financiera y la reforma de la Ley de Arbitraje y Conciliación. A estas reformas le han acompañado retrocesos en las libertades, como la creciente persecución de las minorías, particularmente la musulmana.

Mucho se ha hablado del mantra Vibrant Gujarat, de cuando Modi fue Chief Minister de dicho estado. Ese periodo, de 2001-2011, se caracterizó por unas altas tasas de crecimiento, nunca antes experimentadas. Esto le ha permitido a Modi $\mathrm{Ji}^{4}$ proyectar un modelo similar a escala nacional anunciando retos inalcanzables $^{5}$, como la consecución de «una economía de cinco trillones ${ }^{6}$ de dólares para 2024». Este objetivo no es visto como producto de un visionario, sino que su credibilidad viene avalada por su actuación en Gujarat.

Por su parte, sus detractores señalan de forma objetiva ${ }^{7}$ que no todo el crecimiento de

\footnotetext{
4 El sufijo ji, muy usado en india, implica respeto.

5 Incluso en ausencia de la COVID-19.

6 Trillones americanos, billones en el caso español.

7 Sin olvidar su controvertida actuación en la matanza de los musulmanes de 2002 siendo Chief Minister de Gujarat.
}

Gujarat se debe al factor Modi y, sobre todo, que en dicho periodo los datos de distribución de la riqueza, pobreza, estado de bienestar o igualdad de la mujer, entre otros indicadores, dejan mucho que desear en Gujarat en la comparativa con otros estados.

Cuando Modi fue nombrado por primera vez primer ministro de India, en 2014, una vez asumidos los errores del pasado como Chief Minister, tuvo consciencia de que, si quería granjearse un apoyo mayoritario de los indios, necesitaba focalizarse de una forma importante en la extensa pobreza y desigualdad de un país donde se presentan los mayores contrastes del mundo. Es en este momento y, sobre todo, en su segundo periodo de legislatura, conocido como Modi 2.0, cuando se generaliza un nuevo discurso basado en el crecimiento sostenible e inclusivo, abandonando el antiguo debate de crecimiento vs. distribución de la riqueza ${ }^{8}$.

Modi comparte con su partido, el Baratiya Janata Party (BJP), y con su rama más radical, el Rastriya Swayamsevak Sangh (RSS) ${ }^{9}$, una visión de India que contempla únicamente a la religión hindú (India debería ser Hindustan, la tierra de los hindús, como Pakistán es la tierra de los musulmanes), así como el orgullo de la cultura y la tradición indias.

En la oposición está el antes pujante Partido del Congreso, que desde la independencia sentó las bases de la India moderna. Se trata de un partido laico, multicultural, inclusivo con las minorías, angloparlante y que, por tanto, considera la lengua inglesa como activo fundamental para el país, hecho que le ha permitido el desarrollo de un sector, tecnologías de la $\triangleright$

\footnotetext{
8 Conocido como debate Bhawhati vs. Sen, haciendo referencia a las divergencias entre los dos premios Nobel de Economía.

9 Modi tiene conexiones con el RSS desde los ocho años y entra a formar parte activa del RSS tras la guerra indopaquistaní de 1971.
} 
información y las comunicaciones (TIC), boyante, llevar a cabo una política exterior vecinal más diplomática o contar con una clase política más educada y preparada que la del BJP. No obstante, en los últimos años de su mandato, el Partido del Congreso había caído en la autocomplacencia, la inactividad, la corrupción, la política de subsidios y, por encima de todo, en la ausencia de un líder creíble.

El antecesor de Modi, Manmojan Singh, formado en Oxford y persona respetada, apreciada y discreta, artífice de las reformas de apertura de la economía india de los noventa ${ }^{10}$ que generaron un crecimiento exponencial durante más de una década, no pudo con los males de su partido; había que buscar, por tanto, un sucesor. La presidenta del Partido del Congreso, Sonia Gandhi, siendo consciente de que siempre será, de cara a India, extranjera ${ }^{11}$, pese a ser una Gandhi, dedicó todos sus esfuerzos a hacer de su hijo Rahul un líder indiscutible del partido, digno de llevar el apellido Gandhi, pero no lo consiguió.

Ante el carisma de Modi, el BJP acepta sus mantras y su liberalismo económico, pese a ser, en su esencia, un partido intervencionista y antioccidental. Mientras tanto, Modi intenta rodearse de adeptos con cierta formación económica, espíritu de reforma, defensores de la iniciativa privada y la facilitación del desarrollo empresarial. Por otro lado, Modi comparte el fanatismo nacionalista con el BJP y ha conseguido, con una gran oratoria centrada en un proyecto de una India potente, unida y reformada que mira al futuro, atraer a una amplia mayoría de la población posibilitando su reelección, la

10 Manmojan Singh era en ese momento ministro de Economía de India.

11 Esto contradice a la propia estructura social y tradición india, que considera que, en el matrimonio, la mujer deja de formar parte de su familia, pierde contacto e incluso identidad, y pertenece a la familia del marido. Previo pago, por supuesto, de una dote. cual no se explica en clave de apoyo popular al BJP, sino por el apoyo personal al gurú Modi. Este fenómeno es más patente en las elecciones según los distintos estados, sobre todo en los más poblados, donde el apoyo al BJP se desvanece. Tanto el partido como su líder son muy conscientes de este fenómeno.

Con una oposición desestructurada y sin líder claro a la vista, y una legislatura por delante de tres años, Modi Ji es la esperanza y el futuro de India, o al menos de su mayoría hinduista.

\section{2. ¿Será India la próxima China?}

La comparación entre China e India obedece inevitablemente a dos factores como son que India ha experimentado por largos periodos de tiempo tasas de crecimiento similares a las de China, así como al hecho de que en 2027 se espera que India supere a China en población. Sin embargo, India no será la próxima China. El subcontinente indio tiene que ser entendido en sus propios términos y, por tanto, seguir su propio ritmo. Las comparativas no ayudan a entender al país ni a las oportunidades que puede ofrecer su mercado.

Ningún Gobierno indio será capaz de dirigir la economía de la forma en que China lo hace. Tampoco conseguirá el control sobre la localización de los recursos, hecho intrínseco al éxito económico de China. China es muy disciplinada con su planificación económica derivada de su sistema de un solo partido. Por el contrario, la diversidad cultural y lingüística de India nada tiene que ver con el sustrato Han, base de la mayoría de la población china.

La economía india presenta un nivel de producto interior bruto (PIB) elevado, pero no se puede comparar con el tamaño de la economía china. Para llegar a converger o a superar a $\triangleright$ 
la economía china, esta tendría que colapsar e India mantener tasas de dos dígitos de crecimiento por años. Ninguno de estos escenarios es plausible en este momento.

Por otro lado, China está envejeciendo, con la presión que esto va a provocar sobre el estado de bienestar y el sistema de salud. La edad media de la población en India en 2019 era de 28 años, por lo que la demografía juega a favor de India.

El crecimiento de la economía china se ha basado en el desarrollo de las infraestructuras, la inversión y la industrialización. El crecimiento económico chino se ha apoyado en una de las tasas de inversión más altas del mundo. Dicha inversión ha permitido, por una parte, el desarrollo de nuevas ciudades, la construcción de kilómetros y kilómetros de alta velocidad, aeropuertos y puertos, y, por otra, le ha dotado de un músculo de producción industrial impresionante. China ha sido la fábrica del mundo de los últimos veinte años. Su habilidad para, de forma eficiente y rápida, movilizar lo que produce, tanto internamente como por todo el mundo, ha sido un elemento fundamental de su milagro de crecimiento económico. A fecha de hoy, India, pese a sus esfuerzos, está muy por detrás de China en estos tres frentes.

El cambio del peso en el PIB del sector agrícola $^{12}$ hacia un sector servicios de crecimiento robusto no es extraño en una economía emergente como India. Lo que sí sorprende es el escaso papel que ha jugado el sector industrial en el proceso de desarrollo indio, suponiendo en la actualidad un $27 \%$ aproximadamente del PIB. El sector servicios, con un peso para el caso indio de alrededor del $55 \%$ del PIB, es considerado, en economías en desarrollo y

12 Si bien el sector agrícola supuso en el año fiscal 2018-2019 aproximadamente un $18 \%$ del PIB, este sector emplea a casi la mitad de la población. emergentes, un sector con menor productividad que el manufacturero; no obstante, la productividad del sector servicios indio es comparable con la de China. El sector servicios indio es uno de sus grandes activos.

Se podría pensar que detrás de la política de Make in India y del programa Self-Reliant India subyace el objetivo de convertirse en la fábrica del mundo o mirarse en el espejo del «Milagro del Sudeste Asiático», con un crecimiento basado en las exportaciones y su participación en las cadenas globales de valor. Sin embargo, el modelo indio se basa fundamentalmente en su consumo interno y los servicios. El objetivo fundamental, en este momento, es desarrollar una industria manufacturera propia que cree empleo, conseguir transferencia de tecnología, atraer capital del exterior y abastecer a su enorme y creciente mercado interno. En definitiva, de estas políticas se deriva otro mantra: «India para los indios».

Hay que señalar que, recientemente, dentro de las aspiraciones y mantras prioritarios del país, está atraer la inversión americana, japonesa o taiwanesa que, entre otras, está abandonando China y buscando nuevos emplazamientos en la región. Es interesante señalar que el estado más poblado de India, Uttar Pradesh ${ }^{13}$, ha sido uno de los más activos en atracción de inversión extranjera ${ }^{14}$, ofreciendo grandes cantidades de tierra a las empresas multinacionales, fundamentalmente americanas, que quieren dejar de fabricar en China. No obstante, en la situación de pandemia actual, muchas empresas multinacionales están enfrentándose a restricciones severas de tesorería y de capital y, por tanto, están siendo muy cautelosas antes de hacer algún movimiento. Además, $\square$

\footnotetext{
13 Con una población del tamaño de Brasil.

14 Hay que incorporar, asimismo, los esfuerzos de Andhra Pradesh, también en este sentido.
} 
aunque se pongan a disposición «bancos de tierra» y los costes sean relativamente baratos en el país, es muy improbable que solo por ello las grandes compañías relocalicen parte de las cadenas globales; es mucho más fácil decirlo que hacerlo.

Como se ha señalado con anterioridad, China ofrece conectividad, grandes infraestructuras, logística sofisticada y técnicos; todos ellos requisitos esenciales para cumplir con los requerimientos de calidad y plazos de las empresas multinacionales, mientras que India no está integrada en las cadenas globales de va$\operatorname{lor}^{15}$. La posición india respecto a los acuerdos multilaterales de libre comercio es muy compleja; su política de atracción de inversiones es, cuando menos, volátil y sus recientes medidas proteccionistas no ayudan a crear el marco adecuado. Una mayor apertura del país permitiría, sin duda, explotar su ventaja competitiva en productos intensivos en mano de obra, al tiempo que mejoraría la productividad y se elevaría la innovación.

Resulta de interés añadir que India tiene una diáspora en países como EE UU, Reino Unido, Canadá, Australia, África y el Golfo ${ }^{16}$, que supone un gran activo para el país. En dicha diáspora podemos encontrar desde Premios Nobel a directivos de empresas tecnológicas, investigadores, políticos y gobernantes, que no son comparables en tamaño y nivel intelectual ni educacional, ni tienen la misma influencia en la diáspora china.

No se pueden dejar de resaltar, particularmente en un momento como el actual, las enormes tensiones entre ambos vecinos

15 El sector farmacéutico podría ser la excepción y, en cierto sentido, aunque con distancia y matices, los sectores automoción y textil.

16 Hay que diferenciar entre la «huida de cerebros» a países occidentales, la diáspora del siglo pasado al continente africano, y los movimientos masivos de trabajadores indios, poco formados, a los países del Golfo. (territorial, tecnológico etc.); si bien India no es China, la interacción entre ambos países es máxima. Esto queda puesto de manifiesto por la dependencia india de las importaciones ${ }^{17}$. Destacar también el papel de Nepal como país de complejos equilibrios entre ambos gigantes y las provocaciones e incursiones chinas en India sobrepasando los límites fronterizos y cuya tensión en este momento está en niveles máximos, dado que estamos hablando de dos gigantes nucleares. Asimismo, es manifiesta la hegemonía militar china en posibles operaciones terrestres, mientras que la hipotética supremacía india sería marítima, ya que su Armada podría estrangular los suministros vitales de China al controlar el estrecho de Malaca. Otro punto de fricción bilateral es la influencia china de carácter estratégico en los países vecinos de India, como es el caso de Pakistán y Sri Lanka.

China se ha convertido, con todos los matices necesarios, en el líder de la región con vocación de liderazgo mundial, como pone de manifiesto la iniciativa $\mathrm{OBOR}^{18}$. Sin embargo, la India de Modi no está dispuesta a dejarse intimidar.

India, con sus grandes contrastes y la creencia en su destino, tiene la demografía a su favor, una gran tradición empresarial, una enorme clase media en expansión, gran potencial de mejora en productividad y un gran orgullo del pedigrí de la civilización a la que pertenece. Además, frente a China, y como señalaría el premio nobel indio, el profesor Amartia Sen, India es una democracia parlamentaria modelo Westminster y, por lo tanto, el poder está sometido a sus propios mecanismos de control. Es la mayor democracia del mundo.

\footnotetext{
17 A pesar del boicot encubierto indio a la producción China.

18 Iniciativa china de One Belt One Road.
} 


\section{La India de los grandes números: su población}

Como es sabido, India es la quinta economía más grande del mundo, la tercera en cuanto a PIB en términos de paridad del poder adquisitivo. No obstante, al incorporar su vasta población, se obtiene un desilusionante PIB per cápita de 2.170 dólares. India es una de las economías de mayor crecimiento del mundo, pero también uno de los países con más desigualdades en todos los ámbitos: urbe vs. zona rural, norte de India frente al sur, desigualdad de género, de renta, castas y minorías étnicas y religiosas. Un $10 \%$ de la población india posee el $77 \%$ del total de la riqueza.

En 2050 se prevé que India habrá incrementado su población en 273 millones de almas, con todos los retos que esto implica, en uno de los países más densos en términos de población del mundo. El desafío no es cómo contener el crecimiento de la población, sino cómo conseguir que la población sea competente y productiva para generar riqueza y cómo distribuir esa riqueza de forma equitativa para no dejar a nadie en el camino del progreso.

La población es, en gran medida, la variable esencial de cara al desarrollo y al crecimiento del país, y en torno a ella giran todas sus realidades, fortalezas y desafíos.

Más del $60 \%$ del PIB indio proviene del consumo interno. La clase media india está constituida por entre 300 y 350 millones de personas, y va en aumento. El salario medio se estima que se cuadriplicará entre 2013 y 2030, con las implicaciones que esto puede tener en términos de demanda de bienes de consumo. El rápido crecimiento de la industria del software, donde los indios sobresalen, ha permitido crear una clase media india nueva, abierta y moderna. De hecho, se produce un intercambio fluido, por ejemplo, entre Silicon Valley y su equivalente indio, Bangalore, que ha creado un nuevo consumidor global.

Los números en India son siempre desmedidos. Para 2025 un quinto de la población mundial en edad de trabajar será india. Para 2030 se superará la cifra de los 850 millones de usuarios de internet. En 2035, las cinco ciudades más importantes de India tendrán economías del tamaño comparable a los países de renta media de hoy.

En este momento, India es la cuna de una de las poblaciones más jóvenes del mundo (se estima 31,4 años para 2030). Dicha población, formada adecuadamente, tiene el potencial de incrementar considerablemente su productividad y que esto se traduzca en un mayor crecimiento económico.

El futuro de India depende de su capacidad de crear capital humano y de que haya suficientes puestos de trabajo para dar cabida al millón de indios que se incorporan al mercado laboral cada año. Sin embargo, este es uno de sus mayores retos, ya que la mitad del empleo del país depende de un sector agrícola poco productivo, con grandes carencias educativas, sobre todo en estados con una mayor densidad de población y mayores tasas de fertilidad ${ }^{19}$, por lo que son los que peores resultados obtienen en la creación de empleo, situación que está agrandando las desigualdades territoriales. Así, más de la mitad de los trabajadores indios quedarían, desde el punto de vista de su formación, obsoletos para el año 2022. En consecuencia, urge la necesidad de mejorar la educación y, lo que es más importante, incorporar a la mujer, la mitad olvidada del país, al sistema educativo y al mercado de trabajo indio. $D$

\footnotetext{
19 Noreste de India.
} 
Asimismo, hay que generar un entorno atractivo para minimizar la huida de talento al exterior, una parte muy importante de la, grande en número pero pequeña en proporción, clase india altamente formada.

\subsection{Urbanización: migraciones masivas}

Las ciudades indias se encuentran entre las que tienen mayor densidad de población, pero un menor espacio disponible per cápita del mundo. De media, Mumbai ofrece $4,5 \mathrm{~m}^{2}$ por persona, frente a los $34 \mathrm{~m}^{2}$ que ofrece Shanghái.

Cada minuto migran del campo a la ciudad entre 25 y 30 personas buscando una mejora en sus condiciones de vida. Si esta tendencia se mantiene, la población urbana india alcanzará en 2030 los 600 millones de habitantes. Antes de hablar de los desafíos que este fenómeno va a suponer, hay que señalar que este acontecimiento es muy probable que cree una de las mayores concentraciones de empresas de bienes de consumo, vendiendo desde automóviles hasta productos farmacéuticos, contribuyendo al $75 \%$ del PIB de India en 2030.

En los últimos cinco años, una media de 90 millones de personas ha utilizado el ferrocarril como medio de migración entre estados. Esto implica casi duplicar la tasa de migración producida durante la primera mitad del siglo pasado. Siendo la National Capital Region, en el norte de India, es decir, Delhi, Gurugram y Gautam Budh Nagar, el centro de mayor creación de empleo y, por tanto, el área que presenta mayores tasas de recepción de migración, mientras que Uttar Pradesh (UP), Bihar y Madhya Pradesh continúan siendo los proveedores mayores de mano de obra al resto del país.

Los motivos y tipos de migración varían, desde los ingenieros informáticos altamente formados con destino a los centros de Information Technology (IT) de Bangalore o Hyderabad, a agricultores de UP para trabajar en la construcción en Gurugram. Es impresionante visitar las estaciones de ferrocarril y aeropuertos de las grandes metrópolis indias durante las épicas vueltas a casa en los festivales de Diwali, Holi y Eid.

Estos flujos migratorios presentan enormes desafíos para las ciudades receptoras, ejerciendo una presión cada vez mayor sobre los escasos recursos e infraestructuras de las mismas. Sin lugar a duda, este es uno de los retos más importantes del futuro de India.

Caóticas, complejas, ruidosas... son algunos de los adjetivos que describen a las ciudades indias. También sorprende que en los últimos setenta años se hayan desarrollado diez nuevas ciudades sobre plano: Bhubaneshwar (1946), Chandigarh (1966, diseñada por Le Corbusier), Navi Mumbai (1972), Noida (1976) y Naya Raipur (2000), entre otras.

Adicionalmente, numerosos proyectos de desarrollo de ciudades, que se han llevado a cabo en las diez ciudades principales del país, han puesto de manifiesto importantes retos a los que deberían hacer frente las grandes urbes, retos que abarcan desde la necesidad de un urbanismo planificado hasta la realización de mejoras sustanciales en distintos ámbitos, como sucede con la situación crítica de las infraestructuras, los enclenques servicios públicos, las escasas infraestructuras sanitarias, la deficiente gestión de residuos o la carencia de recursos básicos como el agua potable, etc. Entre estos proyectos destaca el Delhi Mumbai Industrial Corridor (DMCl) que el Gobierno indio lanzó hace más de una década.

EI DMIC es un proyecto de una magnitud impresionante, con un nivel de inversión previsto de 100.000 millones de dólares, y que $\triangleright$ 
tiene como objeto el desarrollo de veinticuatro nuevas ciudades industriales entre la capital política (Delhi) y la financiera (Mumbai).

No podemos olvidar que el alma india está muy unida a su cultura, y particularmente con el BJP en el Gobierno, a su religión, por lo que se está dando especial importancia a la mejora de su patrimonio cultural y espiritual y a las facilidades turísticas, con proyectos como Hriday (doce ciudades de patrimonio cultural en nueve estados), Swadesh Darshan (trece circuitos espirituales temáticos) y Prasad (desarrollo y mejora de trece sitios de peregrinaje).

El Gobierno indio ha llevado a cabo diversas iniciativas a nivel nacional para el desarrollo de infraestructuras en sentido amplio, tales como Amrut (distribución de agua potable e infraestructuras de agua), Swachh Bharat (gestión de residuos, infraestructuras sanitarias básicas y medidas de higiene pública) y la iniciativa Smart Cities (gestión de transporte eficiente, tratamiento de aguas, mejora de las infraestructuras de transporte, embellecimiento de las ciudades...). Mucho queda todavía por hacer, y en India las ideas son siempre más fáciles de concebir que hacerlas realidad.

Los impresionantes atascos de tráfico en ciudades como Delhi, Mumbai y Bangalore son de sobra conocidos a nivel mundial junto con los elevados niveles de contaminación y de accidentes de tráfico. La nueva construcción de carreteras, radiales, rotondas y resto de elementos de conectividad está muy por debajo de las necesidades del país y, sobre todo, de la densidad creciente del número de automóviles. De hecho, cuando se inaugura una infraestructura, esta suele ser insuficiente para cubrir sus objetivos al ser superados por la realidad.

India está obligada a invertir masivamente en infraestructuras. Mientras tanto, y con el objetivo de gestionar el tráfico interurbano, se ha adoptado el mantra moving people, not cars. Más de $300 \mathrm{~km}$ de líneas de metro son operacionales a lo largo de India, $600 \mathrm{~km}$ están en construcción en doce ciudades y otros $500 \mathrm{~km}$ están en fase de estudio. Lo mismo ocurre con las líneas de autobús interurbanas y de media distancia (BRTS, Bus Rapid Transit System), que se están desarrollando en doce ciudades y están en fase de estudio en otras ocho ciudades. El ambicioso proyecto llamado Bharatmala, del Ministerio de Carreteras, se centra en el establecimiento de radiales de circunvalación y bypasses. Delhi, la capital, tiene dos anillos de circunvalación operativos y un tercero planificado. Aparte de extender su red de metro, Delhi está desarrollando su red de tren de media distancia (RRTS, Regional Rapid Transit System) con trenes que se prevé puedan llegar a alcanzar los $180 \mathrm{~km} / \mathrm{h}$ y conectar la capital con ciudades que esperan convertirse en ciudades dormitorio: Meerut, Sonepat o Alwar, como vía de escape para el exceso de densidad de población que soporta la capital india.

Todavía no se ha abordado uno de los puntos más complejos en India, el suelo. El mercado del suelo indio es especulativo por naturaleza. Los actores en el desarrollo de las ciudades (desarrolladores del sector inmobiliario, hoteleros, centros comerciales...) siempre se quejan del engorroso proceso burocrático, no exento de corruptelas, de la obtención de las licencias y del alto precio de la tierra, que convierten los proyectos en inviables desde el punto de vista económico. Los Gobiernos de los estados tienen un largo camino que recorrer en esta problemática.

El Gobierno indio también ha tomado una cierta conciencia de la escasez de viviendas asequibles en las ciudades, al permitir la subvención de los tipos de interés de los préstamos para la vivienda y el modelo de $\triangle$ 
asociación entre los sectores público y privado para los proyectos de construcción de 20 millones de unidades nuevas para 2022. Este tipo de actuaciones afecta a los pocos que están pensando en comprar una vivienda y que además pueden acceder a una hipoteca. Una gota en el océano para la población india.

El futuro de India depende, en buena medida, de la capacidad de transformar unas ciudades ya de por sí con sobredensidad de población. Todas las medidas que los distintos niveles administrativos puedan implementar en esta transformación serán bienvenidas.

«The soul of India lives in its village ${ }^{20}$ ». Esta cita de Mahatma Gandi dejará de tener fuerza si se cumple lo que vaticina el último informe de Naciones Unidas, que estima que la población urbana sobrepasará a la población rural india en 2050. El país no puede cometer el error de abandonar a su ya olvidada minoría mayoritaria, la población rural.

\section{Subcontinente indio, 28 Indias}

A nivel internacional se conocen y aprecian las diferencias culinarias, lingüísticas y culturales entre el norte y el sur de India, pero lo que no es tan conocido son las diferencias en el desarrollo entre ambos grupos, e incluso la diversidad política, motores de crecimiento económico o clima inversor de los veintiocho estados y ocho territorios de la Unión ${ }^{21}$. Las distintas realidades indias varían ampliamente en población, crecimiento económico, tasa de urbanización, recursos naturales, acceso a puertos, regulación medioambiental y calidad de liderazgo. De

20 Algo así como «el alma de India vive en sus pueblos».

21 Tras la creación del estado de Telangana (2014) y la conversión de Jammu-Kashmir en territorio de la Unión, separando Ladack y convirtiéndolo también en un territorio nuevo (31 de octubre de 2019). la tradicionalmente comunista Kerala, con tasas de alfabetización envidiables, pero donde resulta prácticamente inviable emprender, al liberalismo a ultranza gujarati, vibrante en crecimiento, pero con indicadores sociales por debajo de la media. Ambas realidades se sitúan en una escala de bonanza y progreso que no tiene nada que ver con el paupérrimo noreste del país.

Cuando se habla en términos de PIB o de participación en la esfera internacional, unos pocos estados acaparan las cifras. Ocho agrupan más del $60 \%$ de la actividad económica (Andhra Pradesh, National Capital Region-Delhi, Gujarat, Karnataka, Kerala, Maharasthra, Tamil Nadu y Uttar Pradesh). Cinco estados suponen el $70 \%$ de las exportaciones (Maharasthram Gujarat, Karnataka, Tamil Nadu y Telangana). En los últimos diez años, cinco estados han atraído el $70 \%$ de la inversión extranjera directa (Maharastra, Karnataka, Tamil Nadu, Gujarat y Delhi). Y, por último, cinco estados recolectan más del $50 \%$ del GST (Maharashtra, Karnataka, Tamil Nadu, Gujarat y Delhi).

La demografía es una variable muy significativa de cara a valorar las disparidades. Siempre se habla de una India muy joven. No obstante, la edad media de estados prósperos como Kerala y Tamil Nadul es de treinta años, mientras que en los estados de Bihar o Uttar Pradesh (UP), es tan son solo de diecinueve. Mientras las tasas de fertilidad de Kerala y Tamil Nadul están por debajo de la tasa de reposición, UP y Bihar tienen una tasa de fertilidad por encima del tres. En términos de esperanza de vida, Kerala y Tamil Nadu presentan tasas similares a países de renta media, frente a UP y Bihar, que son comparables a países de ingresos bajos.

India sí presenta cierta especialización productiva regional, si bien en términos $D$ 
generales es bastante reciente y ha estado unida a un mayor desarrollo de los estados que han apostado por esta regionalización.

Considerando, por ejemplo, su capital en sentido amplio, Delhi $\mathrm{NCR}^{22}$, más allá de su poder administrativo es un hub económico importante, incluyendo varias zonas económicas exclusivas y clústeres industriales, tales como los centros de servicios tecnológicos de Gurugram y Noida y los hubs manufactureros de Faridabad y Alwar.

Mumbai, capital de Maharashtra, el estado más avanzado y el segundo más poblado, es el centro financiero y empresarial y la meca de la industria del cine indio, sede del RBI (Reserve Bank of India, la autoridad monetaria del país) y de los reguladores financieros, los principales bancos y empresas, a la vez que la puerta para las importaciones del oeste de India. La segunda y tercera ciudades más importantes, Pune y Nagpur, respectivamente, son centros de producción de energía.

No podemos olvidar otros estados menos conocidos como Tamil Nadu, con su capital Chennai, que es el Detroit de India, uno de los diez mayores hub de automoción. Karnataka y su capital Bangalore, el Silicon Valley indio. Andhra Pradesh (AP), que lidera el ranking en India de facilidad para hacer negocios, ha atraído a los mayores actores extranjeros, sobre todo en el sector de la energía. El recientemente creado estado de Telangana lidera junto con AP en facilidad de hacer negocios y empieza a destacar en IT y sector farmacéutico, todo ello creando un ecosistema favorable para las startups. West Bengala es el centro del sector de minería y la puerta para los estados ricos en mineral de Jharkhand, Chattisgarh y

22 National Capital Region no incluye únicamente el Gobierno central de Delhi, sino que afecta a ciertas áreas de los tres estados limítrofes: Haryana, Rajasthan y UP.
Odisha. El estado de Punjab está especializado en la agroindustria.

Los estados indios asumen cada vez mayor número de competencias del Gobierno central. Tradicionalmente, la distribución de poderes entre Gobierno central y estados ha favorecido siempre al centro. Pero la liberalización económica que comenzó en los noventa empezó a cambiar esto.

El Gobierno central establece el marco de las políticas macroeconómicas, tiene las competencias en materia de inversión extranjera y fija las prioridades de gasto público. Mientras que el centro mantiene gran poder financiero $y$ fiscal, incluidos aranceles y el impuesto de sociedades, los estados ostentan la mayor parte de las responsabilidades en la prestación de servicios públicos como educación, salud y resto de servicios básicos. También todo lo que hace la vida de una empresa o autónomo fácil o difícil: el acceso a la tierra, la regulación laboral, la aplicación e interpretación de la regulación, el desarrollo y gestión de las infraestructuras sociales básicas, la política y planes de urbanismo, entre otros.

Tras su experiencia de más de una década como Chief Minister de Gujarat, Modi se ha decantado por un federalismo que dice ser «cooperativo y competitivo", incluyendo también a las ciudades (el denominado subfederalismo) en este mantra. El federalismo competitivo está calando en la sociedad india, sobre todo en los cinco estados que producen el $70 \%$ de las exportaciones del país. No podemos olvidar que muchas de las reformas estructurales más duras, tales como el acceso al suelo o la regulación del mercado de trabajo, dependen en gran medida de los estados. El hito que marcó la reducción de barreras al comercio interno fue la introducción, en 2017, de un impuesto indirecto sobre bienes y servicios común para todo el $\triangleright$ 
país, el GST. La introducción de esta figura impositiva ha aproximado a India a ser un mercado único, de forma que, en este contexto, el capital y la mano de obra se irán hacia aquellos estados que les ofrezcan mejores condiciones y perspectivas de negocio. Los estados están compitiendo, y probablemente ello tenga ventajas, pero India tiene que empezar a tomarse muy en serio la cohesión económica y social y la parte cooperativa. Si no, se cumplirá la paradoja de ser la gran democracia del mundo que olvida a la mayoría de su población.

\section{India, uno de los países más afectados por la COVID-19: situación actual}

La COVID-19, en el caso de India, no deja de ser una de esas enfermedades infecciosas emergentes (EIE) que asolan el país. Quizás la diferencia frente a otras infecciones sea que no distingue clase social, si bien en un país donde cerca de 163 millones de personas carecen de acceso a agua limpia y potable y con un sistema de salud pública minúsculo, por no decir raquítico en términos relativos, la COVID-19 está siendo devastadora entre las clases más desfavorecidas. La actual pandemia está poniendo de manifiesto las grandes carencias de India.

Con fecha 15 de septiembre, y según datos de la OMS, India ha registrado oficialmente cerca de cinco millones de casos de COVID-19 y supera los 75.000 fallecimientos, lo que la sitúa como el segundo país más afectado por la pandemia, después de Estados Unidos. India también lidera la sombría estadística del mayor índice de mortalidad entre sanitarios, con casi seiscientos fallecimientos desde que se desencadenó la epidemia en el país.
Durante el pasado mes, India ha estado registrando los mayores aumentos diarios de casos del mundo y es el país donde la pandemia se está extendiendo con mayor rapidez. Cerca del $60 \%$ de los casos activos proceden de los estados de Tamil Nadu, Karnataka, Andhra Pradesh, Maharashtra y Uttar Pradesh, este último el estado más poblado del país.

La precaria situación del sistema sanitario indio contribuye a agravar la situación, dado que el país cuenta con solo 0,55 camas de hospital por cada mil habitantes, muy por debajo de las 2,80 de Estados Unidos o las 2,15 de Brasil, los países donde la incidencia de la pandemia está siendo más acusada en la actualidad.

No obstante, la tasa de mortalidad del virus (el número de fallecimientos como porcentaje del número de infecciones) es comparativamente más reducida en India. Esta circunstancia puede deberse a que la población del país es predominantemente joven, a que los fallecimientos se retrasan semanas con respecto a los casos detectados, lo que es especialmente importante en el actual momento de transmisión exponencial de la enfermedad para justificar el desfase de la tasa de mortalidad con respecto a los contagios. La baja mortalidad también puede ser un reflejo de que no se estén llevando a cabo las suficientes pruebas diagnósticas. No obstante, el temprano confinamiento y cierre económico del país también puede haber contribuido a contener la expansión del virus, que, al menos en las primeras etapas, tuvo una entrada tardía en India.

El confinamiento y cierre del país fue anunciado por el primer ministro, Narendra Modi, el pasado 24 de marzo, con una duración, en principio, hasta el 14 de abril, aunque se amplió en tres ocasiones (del 15 de abril al 3 de mayo; del 4 al 17 de mayo y del 18 al 31 de $\triangleright$ 
mayo). Se decretaron rigurosas restricciones que paralizaron la mayoría de actividades económicas y condujeron al desempleo a millones de personas. Pese a las estrictas medidas de contención y distanciamiento social adoptadas, el virus se fue propagando por el país. Los primeros focos se localizaron en los núcleos urbanos más poblados, como Delhi y Mumbai.

El cierre provocó un éxodo masivo de asalariados desempleados y trabajadores emigrantes desde las ciudades a sus zonas rurales de procedencia, pese a que en las aldeas las instalaciones sanitarias son mucho más precarias. Este desplazamiento de población contribuyó a la expansión de la enfermedad desde las ciudades, inicialmente más afectadas, a las zonas rurales del país, más pobres y también densamente pobladas, como el estado de Uttar Pradesh.

La pandemia también ha provocado el retorno de la diáspora trabajadora india. EI Gobierno ha lanzado la aplicación Skilled Workers Arrival Database for Employment Support (SWADES), con objeto de facilitar a estos trabajadores que vuelven la posibilidad de encontrar trabajo, pero obviamente las remesas se verán afectadas. Este hecho se une a las serias dificultades que tiene el país para absorber a la masa de trabajadores que entra cada año en el mercado laboral.

También es cierto que la pandemia ha dejado constancia de las carencias que existen, a nivel global, de trabajadores formados en muchos sectores, incluido el sector salud y el de las nuevas tecnologías, donde los indios sobresalen, cuando la movilidad de trabajadores pueda hacerse de forma segura en un escenario pos-COVID-19.

Para mitigar los efectos adversos de la paralización de la actividad económica, el Gobierno anunció un paquete de apoyo fiscal y monetario de un torno al $10 \%$ del PIB de India. Se prevé que las medidas de apoyo estimulen discretamente el crecimiento a medio plazo.

Las medidas restrictivas comenzaron a relajarse en junio, con el fin de revertir el negativo impacto económico y social del confinamiento. La gradual desescalada supuso el cese de los controles fronterizos entre regiones, la reapertura de restaurantes y la reanudación de vuelos internos entre ciudades del país. El significativo incremento de los casos detectados en las últimas semanas ha coincidido con la progresiva reapertura de la actividad económica. Las duras medidas de contención adoptadas paralizaron la actividad económica y recrudecieron los problemas económicos del país. El FMI prevé que la economía de India se contraiga en 2020 en un $4,5 \%$ tras el prolongado cierre de la actividad económica, con una recuperación del $6 \%$ en 2021 . Este abrupto descenso del PIB es una anomalía para una economía que ha experimentado tasas de crecimiento positivas, año tras año, durante los últimos cuatro decenios.

La producción industrial de India, incluyendo sectores como los de manufacturas, electricidad o minería, se desplomó en abril, con la interrupción de la actividad de las fábricas. El sector servicios no fue ajeno a esta tendencia, dado el cierre de la mayoría de negocios, que redujo el número de clientes en los comercios y contrajo considerablemente la demanda. El único sector económico que presentó un crecimiento positivo durante el primer trimestre fue el agrícola, absorbiendo 14 millones de puestos de trabajo de aquellas personas que habían perdido sus empleos durante los meses anteriores.

Mientras que el país sigue sin haber alcanzado el pico de contagios, preocupa que la recuperación económica sea frágil y lento el $\triangleright$ 
retorno a una senda de crecimiento. Es decir, se descarta una recuperación en forma de V.

La pregunta principal que se hacen los indios, al igual que otras partes del mundo, es si estamos al principio, en el medio o al final de la pandemia. Lo máximo que puede esperar India de su Gobierno en el corto plazo es que la enfermedad cause el menor número posible de muertos, que los parados o los desamparados tengan cubiertas sus necesidades básicas o al menos estén en una situación parecida a la previa a la pandemia, y que los problemas de liquidez de las empresas no les lleven a la quiebra.

El medio largo plazo es diferente, ya que se dan cita todos los desafíos, retos, injusticias, incertidumbres, trabas, dificultades, conatos proteccionistas... que ya caracterizaban al subcontinente indio antes de la COVID-19.

\section{El futuro está lleno de retos}

La pandemia nos impide ver con optimismo el futuro económico. En el corto plazo, el objetivo es salir de esta crisis con el menor coste posible. Obviamente, tendrá un efecto sobre las ya maltrechas finanzas públicas indias, sin olvidar el alto nivel de endeudamiento del sector privado, tanto de las empresas como de las familias.

El cierre de la economía ha puesto de manifiesto las enormes carencias del elefante indio, con un raquítico estado del bienestar y una red protectora del Gobierno incapaz de hacer frente a las demandas de su población.

En este contexto, India necesita crecer. Para ello resulta indispensable mantener una estabilidad macroeconómica con políticas ortodoxas $\mathrm{y}$ reformistas.

El país tiene que hacer frente al reto demográfico. Es esencial invertir en educación, en capital humano. India tiene que elevar su productividad y resolver las ineficiencias de su sistema productivo. El Gobierno de India debe luchar contra viejos prejuicios y discriminaciones, y apoyar la entrada de la mujer en la actividad productiva, su papel en la sociedad y su presencia en cargos directivos. Es necesario crear empleo y establecer un sistema de cobertura y protección para los más débiles.

El agua es uno de los mayores retos del país. India tiene grandes reservas de agua, mal aprovechadas, con distribuciones desiguales, contaminadas y propagadoras de infecciones. El cambio climático agrava y acelera la crisis hídrica del país, con cambios previstos en los patrones de los monzones, aumento de las temperaturas, fenómenos meteorológicos más intensos y retroceso de los glaciares en el Himalaya. Las lluvias, cada vez menos constantes, afectarán a la producción de alimentos y energía, especialmente porque India carece de capacidad de almacenamiento para captar las lluvias de los monzones. India debe tomar las riendas de sus recursos naturales y trabajar por un uso, acceso y tratamiento eficiente y sostenible de los mismos.

India presenta una dualidad, con una Administración pública de élite, mal pagada, que mantiene ciertos beneficios sociales, influida por un cierto anacronismo de corte soviético. Frente a esto, existe un sector privado de capitalismo neoliberal. Conviven, por tanto, modelos ideológicos extremos, mientras la cobertura social es enclenque y no universal. La educación y la sanidad privadas cumplen su función para las élites, pero se palpa el desamparo de una gran parte de la población. El país tiene que ampliar y mejorar los bienes y servicios públicos, profundizar en un estado de bienestar que dé una cobertura mínima y trabajar en la cohesión regional y social. 
Los ingenieros informáticos indios están considerados entre los mejores del mundo y están dispuestos a liderar la transformación tecnológica del país. La calidad y profesionalidad de los médicos y enfermeras indios es reconocida a nivel internacional, y son particularmente necesarios en India ante una situación de pandemia como la actual. Lo mismo ocurre con el nivel de formación, capacitación e inteligencia de maestros, profesores y catedráticos, que están muy por encima de los estándares medios mundiales. Estos grupos representan a una parte importante de la diáspora india. El país debe trabajar por retenerlos.

India debe continuar invirtiendo y priorizando las infraestructuras, entendiendo el término en sentido amplio y aprovechando los cambios que los nuevos desarrollos tecnológicos están produciendo: infraestructuras de transporte, energía, agua, telecomunicaciones, transformación digital, cuestiones de logística, gestión de residuos $^{23}$, urbanismo y conectividad. El país debe mantener una política de atracción de inversiones abierta y que aporte seguridad jurídica. Su actitud al respecto ha sido cuando menos volátil, y debe abandonar un mal entendido proteccionismo. Una visión de India de progreso y futuro exige una apertura internacional.

El desarrollo de una industria potente requiere inversión, tecnología y know-how extranjero. Es imprescindible una mejora del clima de negocios, así como reformas en el mercado laboral, la aplicación de políticas fiscales atractivas, la reducción de barreras y trabas al comercio, la apuesta por mecanismos de resolución de disputas que no impliquen judicialización, reducir los niveles corrupción, mejorar la gobernanza, así como reducir la burocracia, entre otras cuestiones.

\footnotetext{
23 Destaca el problema del plástico.
}

No se puede mirar hacia al futuro, en un país como India, sin señalar que los desarrollos tecnológicos abrirán nuevos y muy interesantes mercados y enormes oportunidades al país. India está capacitada para dar un salto tecnológico que puede permitirle hacer frente de una manera eficiente a sus desafíos importantes. Cuestiones como la velocidad de computación, la penetración de los teléfonos inteligentes, la conectividad de los dispositivos, los volúmenes de datos y muchos otros indicadores tecnológicos están aumentando a un ritmo exponencial, no lineal, en el país. El comercio electrónico, la digitalización financiera y el desarrollo del coche eléctrico, entre otros, son realidades que están impactando de forma muy significativa en los sectores productivos indios, en el acceso a bienes y servicios, en el desarrollo de las ciudades, en la conectividad. Es decir, en la sociedad india en su conjunto.

La transformación de la economía india se está produciendo. Su progreso puede ser lento y a veces errático, pero la dirección es clara e irreversible. Los cambios en India son invisibles a simple vista, requieren paciencia, profundizar en sus realidades y perspectiva.

\section{Bibliografía}

CBRE (2019). India 2030 exploring the future.

Chengappa, R. (agosto de 2020). The Modi Mantra. What is the secret behind the unwavering popularity of the prime minister at a time when the nation is riddled with multiple crises. India Today.

International Monetary Fund (2019). India 2019 Article IV consultation.

International Monetary Fund (2020). Policy responses to COVID-19: India. 
International Monetary Fund (2020). A Crisis like no other, an uncertain recovery.

Ministry of Finance, Government of India (2020). Economic Survey.

Pranav, D. (enero de 2018). India preparing for the biggest human migration on the planet. Invest in India.

Roy, A. (2018). The Middle Class in India: From 1947 to the Present and Beyond. Association for Asian Studies, 23(1).

Singh, P., Ravi, S., y Chakraborty, S. (marzo de 2020). COVID-19: Is India's health infrastructure equipped to handle an epidemic? Brookings.
World Bank (2020). Doing Business 2020.

World Bank (2020). World development report 2020.

UBS (July 15, 2020). Is India the New China?

United Nations (2019). World population prospects 2019.

\section{Páginas web consultadas}

Confirmed COVID Cases. COVIDIndia.org, modificado por última vez el 15 de septiembre 2020. https://covidindia.org/

Oxfam.https://www.oxfam.org/en/india-extreme-inequality-numbers 
